https://doi.org/10.7559/gestaoedesenvolvimento.2019.375

Data de receção: 09/05/2019 Data de aceitação: 12/07/2019

\title{
O MARKETING INTERNO COMO ESTRATÉGIA PARA MOTIVAR OS COLABORADORES: UM ESTUDO DAS PMES DA REGIÃO DE LAFÕES
}

\section{INTERNAL MARKETING AS A STRATEGY TO MOTIVATE EMPLOYEES: A STUDY OF THE LAFÕES REGION}

\author{
António José Oliveira ${ }^{1}$ orcid.org/0000-0002-8609-636X \\ Clotilde Passos ${ }^{2}$ orcid.org/0000-0002-2924-0484 \\ Célia Ribeiro ${ }^{3}$ orcid.org/0000-0002-1000-6890
}

\begin{abstract}
Resumo: Atualmente, as organizações devem compreender que para alcançar o cliente externo, primeiro é necessário que se alcance o cliente interno, isto é, devem praticar o marketing interno. O presente estudo tem como objetivo verificar se as PMEs da Região de Lafões praticam marketing interno e de que forma este conceito é assumido como uma estratégia para motivar os colaboradores. Neste sentido, o estudo desenvolveu-se segundo uma metodologia qualitativa, descritiva e exploratória, através da aplicação de um questionário às PMEs da Região de Lafões. A amostra compreende dez empresas, que praticam marketing interno. Concluiu-se que as empresas que praticam marketing interno utilizam várias estratégias para motivar os seus colaboradores como: comunicação e partilha de informação, promoção do envolvimento e relacionamento entre os colaboradores na realização das tarefas, pratica de reconhecimento, confiança, valorização, elogio e compromisso, desenvolvimento do espírito de equipa, liderança, motivação sistemas de avaliação de desempenho $e$
\end{abstract}

1 Mestrando em Gestão, especialização em Gestão de Negócios da Universidade Católica Portuguesa, Viseu. E-mail: aj.oliveira@ outlook.pt

2 Professora Auxiliar da Universidade Católica Portuguesa, Viseu. E-mail: clotilde.passos@gmail.com

3 Doutorada em Psicologia, área de especialidade em Psicologia Pedagógica. Professora Auxiliar da Universidade Católica Portuguesa - Viseu. E-mail: cribeiro@viseu.ucp.pt 
criação de ações de "Team building", que são por estas, consideradas importantes para a prática e sucesso do marketing interno e motivação dos colaboradores.

Palavras-chave: Marketing interno, motivação, Região de Lafões.

\begin{abstract}
Currently, organizations must understand that, to reach the external costumer they must, first reach the internal costumer, that is, they must practice internal marketing. The present study has the objective to verify if the SMB's of the Lafões Region practice internal marketing and in which form this concept is assumed as a strategy to motivate the collaborators. In this sense, the study was developed according to a qualitative, descriptive and exploratory methodology, through a questionnaire provided to the collaborators of SMB's of Lafões Region. The sample comprises of ten companies, which practice internal marketing. It was concluded that the companies that practice internal marketing apply various strategies to motivate their collaborators such as: communication and information sharing, promoting the involvement and relationship between collaborators in task accomplishment, practicing recognition, trust, valorization, compliment and commitment, developing team spirit, leadership, motivation, performance evaluation and team building. These are considered important in practicing internal marketing and collaborator motivation.
\end{abstract}

Keywords: Internal Marketing, motivation, Lafões Region.

\title{
INTRODUÇÃO
}

O marketing interno pode ser definido como o conjunto de ações de marketing orientadas para os colaboradores e para os clientes internos, com a finalidade de promover entre eles, valores orientados para alcançar um determinado objetivo (Silva, 2013).

A motivação dos colaboradores tem tido um papel importante nas organizações. Esta é fundamental, para que os colaboradores alcancem o 
máximo do seu potencial e maximizem o seu desempenho (Ribeiro, Passos \& Pereira, 2018).

A motivação é baseada, fundamentalmente, em experiências emocionais positivas, evitando as experiências negativas. $\mathrm{O}$ conceito de positivo ou negativo varia de indivíduo para indíviduo, do seu estado psicológico no momento, independentemente das normas sociais (Ribeiro et al., 2018).

A procura pelo aumento da produtividade e do rendimento geral dentro das organizações levou à necessidade de motivar os colaboradores, tendo em consideração as suas diferenças. Para que os colaboradores se sintam motivados é necessário que se considerem parte importante da mesma e não somente cumpridores de regras estabelecidas para atingir um determinado objetivo (Vicente, Cataneo, Volpato, Carvalho, Vieira \& Zilli, 2017). Assim, o objetivo deste estudo é verificar se as PMEs da Região de Lafões praticam o marketing interno e de que forma este conceito é assumido como estratégico para motivar os colaboradores.

\section{ENQUADRAMENTO TEÓRICO}

\subsection{Marketing Interno}

O Marketing defende que uma organização para se desenvolver e criar produtos de forma a satisfazer as necessidades dos seus clientes, deve fazê-lo através de um conjunto de atividades, que permitam a esta, atingir os seus objetivos (Lindon, Lendrevis, Rodrigues \& Dionísio, 2011). Segundo esta conceção, os clientes são os elementos mais importantes de uma organização, sendo também, o ponto de partida para qualquer estratégia empresarial. No passado, o marketing era tido como uma atividade que se limitava à venda e distribuição física de produtos. Com o passar dos tempos, as empresas perceberam que mais importante do que vender uma mercadoria/produto, era realizar a análise prévia das necessidades do mercado, para posteriormente, decidir que produtos conceber e a que preços (Lindon et al., 2011).

O marketing passou por uma evolução clara, onde se podem distinguir cinco fases distintas : fase de produção, vendas, marketing, mercado e relacional (Ferreira, Marques, Caetano, Rasquilha \& Rodrigues, 2015). Na primeira fase, ótica de produção, o importante era produzir e tornar 
disponíveis bens, de modo a satisfazer a procura de produtos básicos, geralmente superiores à oferta. Na segunda, ótica de vendas, o mais importante era vender para continuar a produzir, a prioridade estava no empenho da força comercial para atingir resultados. Na terceira fase, ótica de marketing, o mais importante era satisfazer as necessidades do mercado e atingir os objetivos da empresa, a prioridade era a identificação das necessidades do consumidor, o que exigia um maior esforço de marketing para atingir os resultados e satisfazer o mercado. Na quarta fase, ótica de orientação de mercado, o foco era identificar as necessidades e desejos dos clientes, com vista a maximizar o seu grau de satisfação. A última fase, marketing relacional, centra-se na atenção da empresa para a fidelização dos clientes atuais, com vista a construção de um bom relacionamento de longo prazo (Maçães, 2017). Muitas organizações já entenderam que, para alcançar o cliente externo, primeiro é imprescindível que se alcance o cliente interno, e é neste contexto, que surge o desenvolvimento do marketing interno (Reis, Brugnerotto, Sevilha, Cremonezi \& Oswaldo, 2018).

O marketing interno é uma modalidade de marketing, cuja base está centrada nos colaboradores de uma organização, os quais são encarados como clientes internos. Esta filosofia permite estimular a motivação, mobilização e gestão dos membros da organização, no sentido de disseminar valores orientados para a satisfação dos clientes, facilitando a implementação de mudanças organizacionais (Reis et al., 2018). De acordo com Foreman e Money (1995, citados por Rodrigues, Queirós \& Pires, 2016), existem três componentes de marketing interno: visão, a qual se relaciona com a comunicação da visão e a crença dos colaboradores sobre a organização; a recompensa, que corresponde aos critérios associados ao sistema de recompensas; e desenvolvimento dos colaboradores, ou seja, as suas capacidades, conhecimento e desempenho, à razão da realização das suas tarefas.

\subsection{Marketing Interno e Motivação dos Colaboradores}

A motivação é a vontade que um indivíduo tem em se empenhar, com vista à realização de objetivos de uma organização. Constitui um grande desafio para os gestores das empresas, por não ser uma tarefa fácil, uma vez que as empresas são todas diferentes e por não haver dois indivíduos 
iguais (César, 2014). A responsabilidade de captar, capacitar e gerir os colaboradores, de modo a que cada indivíduo se integre no grupo, na procura da satisfação interna e externa da organização, reside na motivação. Por isso, é essencial uma boa estratégia de comunicação (Teixeira, 2013). Neste sentido o desenvolvimento da prática de marketing interno pode contribuir para o bom desempenho individual e organizacional.

Os gestores têm como desafio transformar os colaboradores em parceiros, sem esquecer que uma estrutura democrática depende da liberdade de informação, do incentivo à criatividade e da liberdade de ideias e opiniões (Cervi \& Froemming, 2017). O marketing interno pode funcionar como estratégia de gestão, possibilitando maior identificação organizacional e mais sucesso na concretização dos objetivos (Cervi \& Froemming, 2017). O sucesso de uma organização depende dos indivíduos que a compõem. Não existem organizações, se não existirem pessoas motivadas, empenhadas e capacitadas para a realização dos seus objetivos (César, 2014).

\section{METODOLOGIA}

Para dar-mos resposta ao objetivo do estudo, optou-se por uma abordagem qualitativa, descritiva e exploratória pretendendo-se, assim, desenvolver e esclarecer alguns conceitos proporcionando uma visão geral do tema e, assim, abrir caminho para novas investigações dentro do mesmo tema (Coutinho, 2014; Gil, 2008).

Para a recolha de dados recorremos a um questionário, adaptado de Guimarães (2012), constituído por duas partes, a primeira permite efectuar a caracterização da amostra e a segunda é constituída por oito perguntas abertas relativas à implementação, pratica, medidas e contributo do marketing interno. O questionário foi enviado por email e aplicado presencialmente nas empresas, na Região de Lafões, que abrange os concelhos de Oliveira de Frades, S. Pedro do Sul e Vouzela. Neste sentido, a população em estudo é constituída por todas as PMEs da região de Lafões, num total de 300 empresas. A amostra não-probabilística é composta por 10 empresas que responderam à nossa solicitação. A amostra é constituída por 10 empresas, como se apresenta na tabela I. 


\section{Tabela I}

Caracterização da amostra

\begin{tabular}{|c|c|c|c|c|}
\hline Empresa & $\begin{array}{c}\text { Ano da } \\
\text { Constituição }\end{array}$ & Área de Atividade & Localização & $\mathrm{N}^{\circ}$ de colaboradores \\
\hline Sosel, S.A. & 1990 & Mediação de seguros & $\begin{array}{c}\text { Oliveira de } \\
\text { Frades }\end{array}$ & 34 colaboradores \\
\hline $\begin{array}{l}\text { Construções Laurindo de } \\
\text { Almeida, Lda. }\end{array}$ & 1989 & Construção Civil & $\begin{array}{l}\text { Oliveira de } \\
\text { Frades }\end{array}$ & 25 colaboradores \\
\hline $\begin{array}{l}\text { Sopil, Sociedade Produtora de } \\
\text { Pinto, S.A. }\end{array}$ & 1967 & Avicultura & $\begin{array}{c}\text { Oliveira de } \\
\text { Frades }\end{array}$ & 43 colaboradores \\
\hline TEAGA II, Lda. & 2011 & Construção Civil & $\begin{array}{l}\text { Oliveira de } \\
\text { Frades }\end{array}$ & 70 colaboradores \\
\hline Pereira \& Ladeira, Lda. & 1997 & $\begin{array}{l}\text { Fabrico de artigos de } \\
\text { mármore e de rochas } \\
\text { ornamentais }\end{array}$ & $\begin{array}{l}\text { Oliveira de } \\
\text { Frades }\end{array}$ & 190 colaboradores \\
\hline Avizela II, S.A. & 1998 & Avicultura & Vouzela & 15 colaboradores \\
\hline $\begin{array}{l}\text { Constálica, Elementos de } \\
\text { Construção Metálicos, S.A. }\end{array}$ & 2004 & $\begin{array}{c}\text { Fabrico de elementos } \\
\text { metálicos de } \\
\text { construção }\end{array}$ & Vouzela & 30 colaboradores \\
\hline T\&T, Lda. & 1993 & $\begin{array}{c}\text { Instalação, } \\
\text { reparação, } \\
\text { manutenção e } \\
\text { assistência técnica e } \\
\text { desmantelamento de } \\
\text { equipamentos fixos } \\
\text { de refrigeração }\end{array}$ & Vouzela & 41 colaboradores \\
\hline Termalistur, S.A. & 2004 & $\begin{array}{l}\text { Atividades de } \\
\text { termalismo }\end{array}$ & São Pedro do Sul & $\begin{array}{c}\text { Entre } 103 \text { a } 194 \\
\text { colaboradores }\end{array}$ \\
\hline Silva \& Carvalhas, Lda. & 1960 & $\begin{array}{l}\text { Comércio de pneus, } \\
\text { lubrificantes, gás, } \\
\text { combustiveis e } \\
\text { serviços associados }\end{array}$ & São Pedro do Sul & 25 colaboradores \\
\hline
\end{tabular}

Verificaram-se algumas dificuldades, também citadas por Fortim (2009) e Gil (2008), nomeadamente a fraca taxa de respostas obtidas. As respostas obtidas permitiram efectuar a caracterização do perfil sociodemográfico dos inquiridos. Assim, 80\% dos respondentes são do género masculino e $20 \%$ do feminino. A idade mínima de 24 anos e a idade máxima é de 65 anos. Quanto às habilitações literárias, 50\% tem uma licenciatura, $20 \%$ têm o $12^{\circ}$ ano e $30 \%$ outras formações académicas. Relativamente às funções desempenhadas na empresa, $50 \%$ são gerentes, $10 \%$ gestão de recursos humanos, $10 \%$ gestão financeira, $10 \%$ gestão da qualidade, $10 \%$ gestão de marketing e $10 \%$ administrativa. Relativamente à idade das empresas, varia entre o valor mínimo de 8 anos e o valor máximo de 59 anos. A idade média das empresas situa-se nos 27,7 anos. Quanto ao número de colaboradores das empresas o valor mínimo é de 15 e o valor máximo é de 190, com uma média de 57,6 colaboradores. 
Para completar a informação sobre a população em estudo recorreu-se à base de dados da eInforma que contem informação sobre todas as empresas da Região de Lafões.

\section{APRESENTAÇÃo, ANÁLISE E DISCUSSÃo DE RESULTADOS}

Passamos a apresentar, por empresa, uma síntese das informações obtidas, tendo por base o objetivo central desta investigação.

A "Sosel, S.A.” situa-se em Oliveira de Frades, dedica-se à mediação de seguros e foi constituída em 1990. Atualmente possui 34 colaboradores. A empresa pratica marketing interno, tendo a implementação do mesmo como principais objetivos: a "notoriedade da empresa", "motivação dos colaboradores" e a "criação de cultura da empresa". A empresa considerou importante praticar o marketing interno, pois pretende ter uma "gestão mais humanizada", em que se aplica o espírito cooperativo na relação com o cliente interno. As medidas que foram implementadas no âmbito do marketing interno foram, a "implementação de reuniões internas", de forma a discutir problemas internos e em conjunto supera-los ; reuniões de quadro anual, nas quais desenvolvem atividades de "team building" com o objetivo de motivar os trabalhadores, aumentar a compreensão dos processos e resultados. A empresa possui 11 escritórios entre Viseu e Aveiro e como forma de aproximar todos os colaboradores, decidiu implementar o marketing interno. Este tem contribuído para a motivação dos colaboradores, na medida em que há um maior relacionamento entre si, maior colaboração e maior envolvimento entre todos. Através do feedback dos colaboradores e das reuniões que a empresa promove, é possível fazer os ajustamentos necessários, levando à satisfação dos colaboradores. O marketing interno contribui para a gestão da cultura organizacional e inovação da gestão, pois, os colaboradores sentem orgulho e ligação à empresa. Como referido anteriormente, as reuniões promovidas pela empresa, permitem ao administrador fazer ajustamentos necessários, para que os colaboradores fiquem satisfeitos. A empresa está assente numa cultura forte, em que existe entrega e orgulho por fazer parte da equipa Sosel. Os colaboradores reveem-se positivamente no projeto e no estatuto que a empresa possui. 


\section{António José Oliveira, Clotilde Passos e Célia Ribeiro}

Contudo, o administrador admite, que pelo facto de a empresa ter adquirido escritórios recentemente, ainda não houve o tempo necessário para cultivar as características anteriormente referidas.

A empresa "Construções Laurindo de Almeida, Lda." situa-se na Zona Industrial de Oliveira de Frades. O setor de atividade é a construção civil. Tem atualmente 25 colaboradores e foi constituída em 1989. Esta empresa pratica marketing interno, tendo como objetivos melhorar o serviço ao cliente e o relacionamento entre empresa e cliente, servindo-os com a melhor qualidade possível. A empresa considera importante praticar marketing interno, pois, com trabalhadores satisfeitos, que "vestem a camisola" da empresa, torna-se mais fácil satisfazer as necessidades e expectativas dos clientes. Foram implementadas medidas de marketing interno, através da "comunicação e transparência". Os colaboradores estão por dentro dos acontecimentos importantes da empresa, bem como de todas as conquistas e partilhas. O marketing interno desenvolvido pela empresa contribui para que exista uma "relação de partilha", "reconhecimento e comunicação entre a empresa" e os colaboradores". O facto de trabalharem num bom ambiente de trabalho dá mais rendimento à empresa. A implementação de mudanças organizacionais torna-se mais fácil, pois, a existência de uma boa comunicação permite que os colaboradores participem na organização dos trabalhos, tornando-os "conscientes das tarefas a executar". Como todos os colaboradores trabalham na empresa há mais de 20 anos, existe uma convivência, cumplicidade e respeito entre todos, o que permite que a empresa tenha uma maneira de agir e interagir própria, especialmente com os clientes.

A "Sopil, Sociedade Produtora de Pinto, S.A." situa-se na Zona Industrial de Oliveira de Frades. A empresa tem como setor de atividade, a avicultura. Atualmente conta com cerca de 43 colaboradores e foi constituída, em 1967. A empresa pratica marketing interno com o objetivo de "motivar e satisfazer os colaboradores". O facto de ser uma empresa familiar e dos colaboradores já lá trabalharem há muitos anos, torna importante a pratica do marketing interno, pois, para além de colaboradores, os trabalhadores são considerados "família". Considera ainda, que para satisfazer o cliente externo é necessário primeiro motivar 
e depois satisfazer as necessidades do cliente interno. Algumas medidas implementadas de marketing interno foram a realização de ações de "team building", como o jantar de natal e o contacto diário com todos colaboradores. O marketing interno desenvolvido pela empresa contribui para "motivar os colaboradores", para "melhorar o seu relacionamento" e proporcionar um "maior envolvimento na realização das tarefas". O facto da gestora de recursos humanos ser uma das administradoras, facilita o contacto entre colaboradores e administradores. Consegue assim, melhorar a organização da empresa e aumentar a satisfação na realização das tarefas. A gestora assimila todas estas questões dos colaboradores e faz os ajustamentos necessários, para que estes fiquem satisfeitos e motivados, envolvendo-se ativamente na consecução dos objetivos da empresa. A Sopil, S.A implementa uma "cultura humanizada", assente em "relações pessoais muito fortes".

A “TEAGA II, Lda." situa-se na Zona Industrial de Oliveira de Frades. A empresa é do setor da construção civil, tem cerca de 70 colaboradores e foi constituída em 2011. A empresa pratica marketing interno, tendo como principal objetivo o foco no cliente interno, pois, considera que este é o grande veículo de sucesso da empresa. A prática de marketing interno deve-se ao facto de entender que este é "benéfico para todos". Trata-se, no fundo, de uma base para "sustentar bons resultados". Medidas como "partilha, confiança e valorização", são considerados valores importantes para a implementação do marketing interno. Se estes se sentirem uma parte essencial da empresa, não apenas um número, sentem-se mais motivados e envolvidos com a dinâmica da mesma. Assim, cada colaborador tem a sua missão pessoal, o propósito do seu trabalho, contribuindo para a manutenção, sustentabilidade e crescimento da empresa. A empresa considera que o marketing interno "facilita a implementação de mudanças organizacionais", tais como, o preenchimento de mapas essenciais para o dia-a-dia, ou mesmo, para o desenvolvimento do trabalho em equipa.

A empresa "Pereira \& Ladeira, Lda." situa-se Zona Industrial de Oliveira de Frades e dedica-se ao fabrico de artigos de mármore e de rochas ornamentais. Foi constituída em 1997 e tem cerca de 190 colaboradores. A empresa pratica marketing interno tendo como principal 
objetivo "tornar os colaboradores mais conscientes do valor produzido", para que tenham consciência do seu real valor, de forma a "aumentar a autoestima profissional". As medidas implementadas no âmbito do marketing interno foram a "partilha de elogio", por parte dos clientes. Aproveitam-se esses elogios para revelar internamente falhas e defeitos reconhecidos, por forma a "incrementar a qualidade do produto". A estratégia utilizada para implementar mudanças organizacionais, segundo o gerente, só será possível através de uma liderança vincada. A consciencialização da existência de uma "liderança motivadora" e não pactuante com resistências, leva a que as mudanças organizacionais aconteçam. Uma "liderança forte", que consiga o reconhecimento por parte dos colaboradores, aliada ao reconhecimento e ao desenvolvimento de uma autoestima profissional, "facilita a inovação dos métodos de gestão". Esta empresa tem uma cultura assente em "tirar de cada elemento o que de mais positivo tem", dando o melhor de si próprio.

A “Avizela II, S.A.”, situa-se em Pés de Pontes, Vouzela. O setor de atividade é a avicultura, ou seja, a produção e a comercialização de ovos de consumo, essencialmente ovos alternativos. Tem atualmente 15 colaboradores e foi fundada em 1998. A empresa pratica marketing interno, tendo como objetivo a "motivação dos colaboradores" para as novidades do setor. A razão que levou a empresa à prática de marketing interno foi a mudança de mercado, isto é, para se "adaptar às exigências do mercado" começou por motivar os colaboradores. As medidas implementadas foram a "formação e a informação". Os contributos do marketing interno desenvolvido pela empresa foram a "partilha e a comunicação entre todos". Os colaboradores têm consciência do que se passa no mercado e o que é exigido para atingir os objetivos. Esta prática de marketing interno permite à empresa a "implementação de novos métodos de trabalho". A "Avizela II, S.A" é uma empresa familiar assente numa cultura humanizada e em relações pessoais muito fortes.

A “Constálica, Elementos de Construção Metálicos, S.A." situa-se na Zona Industrial de Vouzela. A empresa fabrica elementos metálicos de construção, conta com cerca de 30 colaboradores e foi constituída em 2004. Pratica marketing interno e o objetivo desta implementação está relacionado com o potenciar do crescimento e desenvolvimento da 
empresa, tendo por base a opinião dos seus colaboradores. A razão que levou a empresa a praticar o marketing interno está relacionada com uma questão de "visão, bem-estar e sentido de envolvimento por parte dos colaboradores". Uma das medidas para a implementação do marketing interno foi a criação de um projeto, com o objetivo de projetar a empresa a 10 anos. O marketing interno contribui para a motivação dos colaboradores, nomeadamente, ao nível de "compromisso, espírito de equipa, envolvimento e bem-estar". Este contribui para a implementação de "mudanças organizacionais", através da "melhoria de processos, procedimentos e satisfação de clientes". O marketing interno contribui, assim, de forma positiva, para a cultura organizacional e inovação da gestão. A cultura organizacional da empresa está assente em forte inovação e melhoria constante.

A empresa "Termalistur, S.A." situa-se em São Pedro do Sul. A empresa dedica-se a atividades de termalismo. Foi constituída em 2004 e tem entre 103 a 194 colaboradores, de acordo com a época do ano. A empresa pratica marketing interno, tendo como principal objetivo, "simplificar a criação e desenvolvimento dos relacionamentos internos", não só a nível da empresa, administração, colaboradores, mas também, entre os mesmos. A razão pela qual, a empresa decidiu implementar marketing interno foi por considerar importante "atrair, desenvolver, motivar e reter colaboradores qualificados", através da oferta de um emprego que satisfaça as suas necessidades. "Criar relacionamentos saudáveis, duradouros e produtivos", através de uma "comunicação democratizada". Algumas das medidas de marketing interno implementadas foram: ações de "team building" como passeios em grupo, jantares, atividades desportivas, etc. Realiza também, reuniões periódicas com os colaboradores para a comunicação de informações relativas à situação da empresa, de forma a conhecerem os seus objetivos e o papel que têm que desempenhar para atingir essas metas. Quanto mais motivados por uma causa, estimulados e principalmente ouvidos, considerados e respeitados pela empresa, maior será o nível de satisfação e motivação dos colaboradores, relativamente às funções que desempenham. A circulação de informação entre a empresa e os colaboradores é importante, por conseguinte, tem de ser feito um esforço 
planeado, para ultrapassar toda e qualquer resistência à mudança, motivando e integrando os colaboradores, para uma maior orientação e satisfação dos clientes.

A cultura organizacional de uma empresa só é saudável, quando inclui a valorização da diversidade, privilegiando a comunicação das políticas e dos objetivos da empresa, tendo em conta a visão dos colaboradores, estimulando o orgulho e entusiasmo pela empresa, dando prioridade à criação de oportunidades de desenvolvimento e valorização das contribuições de cada um, para o sucesso. A empresa tem uma "cultura organizacional integradora", promovendo a "harmonia e a homogeneidade internas". A cultura da empresa passa pela "criação e manutenção da coesão e empenho dos colaboradores", fomentando o espírito de equipa, crença na importância e valor da criatividade, da inovação, recetividade às mudanças, capacidade adaptativa e crescimento, e aquisição de recursos; definição de objetivos claros, bem definidos, de curto alcance, procurando a maximização dos resultados e pela adoção de valores de respeito pelas regras, ordem, hierarquia e segurança/estabilidade.

A “T\&T, Lda." situa-se no Castro de Campia, Vouzela. A empresa dedica-se à instalação, reparação, manutenção e assistência técnica e desmantelamento de equipamentos fixos de refrigeração. Tem atualmente 41 colaboradores e foi fundada em 1993. A empresa pratica marketing interno com o objetivo de "motivar e satisfazer os colaboradores", e ainda, "criar um bom clima organizacional". A razão pela qual a empresa decidiu praticar marketing interno foi porque para alcançar o foco pretendido - o cliente externo - é necessário "cuidar" do interno, "criando uma proximidade com cada colaborador". Algumas medidas implementadas de marketing interno foram: a realização de ações de "team building" como o almoço realizado todas as sextas-feiras entre colaboradores e gerência e a formação conjunta, que permitiu criar relacionamento e “cultivar cultura organizacional". A motivação está relacionada com o marketing interno, pois, permite um maior envolvimento do desempenho das tarefas e satisfação na realização das mesmas. $\mathrm{O}$ marketing interno contribui para facilitar a implementação de mudanças organizacionais, através da "divulgação e partilha de informações" da empresa com 
colaboradores, o que leva a que estes, se sintam mais envolvidos e reconhecidos. A cultura organizacional desta empresa assenta no alinhamento de todos os colaboradores, com os objetivos da empresa, a passarem pela preocupação com os resultados, que se prentendem maximizar.

A empresa "Silva \& Carvalhas, Lda." situa-se em São Pedro do Sul e dedica-se ao comércio de pneus, lubrificantes, gás, combustíveis e serviços associados. Foi constituída em 1960 e comporta, no momento, 25 colaboradores. A empresa pratica marketing interno, com o objetivo de: "planear os recursos humanos" e a "gestão de carreiras", adaptar a estrutura humana às exigências do mercado atual e possibilitar uma boa prática de recrutamento. Decidiu implementar o marketing interno, pois considera que os colaboradores são o interface com os clientes. Algumas das medidas implementadas no âmbito do marketing interno foram a formação direcionada a cada colaborador e os sistemas de avaliação de desempenho. O marketing interno desenvolvido pela empresa contribui para a "motivação dos colaboradores", através do programa de avaliação de desempenho trimestral e correspondente contrapartidas financeiras. O marketing interno permite, ainda, aumentar o compromisso do colaborador com o projeto e a estratégia da empresa, e também, a implementação de mudanças organizacionais. A empresa tem como foco as necessidades dos clientes, estando sempre atenta à inovação e às melhores práticas dos diversos setores, onde opera.

A localização geográfica da região de Lafões permite beneficiar as empresas de vários fatores positivos, no que respeita à criação de valor para a envolvente externa e interna, o que conduz ao desenvolvimento dos concelhos, das economias locais e dos empregos. Esta representa um recurso que favorece contactos e a comunicação com o exterior. Facilita, também, a comercialização dos produtos domésticos, pois está próxima de grandes centros de consumo, e tem fácil acesso às vias de comunicação, o que atrai investimento para a região (Reis et al., 2018). O bom desenvolvimento do marketing interno por parte destas organizações favorece a organização e os indivíduos, pois a cultura organizacional será reforçada e a convergência de objetivos da organização e indivíduo bem enfatizada (Reis et al., 2018). De acordo com as entrevistas realizadas, foi possível compreender que as empresas que praticam marketing interno 
atribuem uma importância redobrada aos seguintes valores: poder da comunicação, partilha, envolvimento e relacionamento entre colaboradores, reconhecimento, confiança, transparência, valorização, compromisso, espírito de equipa, informação, liderança, motivação e sistemas de avaliação de desempenho.

De acordo com Cervi \& Froemming (2017), para melhorar a relação com os clientes, a empresa pode optar pela implementação do marketing interno, uma vez que este oferece diretrizes sobre como esta e outras ferramentas devem ser usadas, para melhorar o desempenho do marketing interno, por meio de colaboradores capacitados e focados no cliente. Deve, também, avaliar o desempenho dos seus colaboradores, tendo em conta as funções que exercem, para assim compreender, quais os fatores que não os satisfazem (Vicente et al., 2017). Os administradores das empresas contactadas consideram que a motivação é um elemento importante para o bom funcionamento das organizações. Consideram, também, que os indivíduos motivados apresentam maior comprometimento com a organização à qual estão vinculados. Um claro entendimento sobre as dinâmicas de motivação permite uma intervenção objetiva no processo de gestão de pessoal, visando compatibilizar a produtividade dos colaboradores com os objetivos da empresa (Patrick, Gomes, Serafim \& Silva, 2017). A maioria dos responsáveis das organizações que privilegiam uma ou outra teoria da motivação, que lhe pareça a mais adequada, de acordo com as suas convicções e anseios, acabará na prática por dar "mão" a várias técnicas (Cunha et al., 2016). A motivação associada a necessidades, incentivos, expectativas, objetivos individuais, reforços positivos, reconhecimento, tomada de decisão, leva à criação de uma cultura organizacional baseada no compromisso, envolvimento dos colaboradores na realização das tarefas e no alcance dos objetivos organizacionais (Freire, Woehl, Catapan \& Bonfim, 2016).

\section{CONCLUSÃO}

Este estudo procura contribuir para a prática e sucesso empresarial, ao ampliar o conhecimento sobre o papel do marketing interno, já que o seu estudo ainda é recente, pouco significativo e os estudos sobre a sua implementação são escassos. 
A motivação dos colaboradores é importante para o sucesso das organizações (Ribeiro et al., 2018).

Um grande contributo para a prática empresarial é levar os responsáveis das organizações á prática e á utilização de novos métodos e técnicas de motivação.

Os dados recolhidos permitem concluir que as empresas vêm no marketing interno uma ferramenta que possibilita a inovação e melhoria dos processos, a implementação de novos métodos de trabalho, criação de relações pessoais fortes, que aumenta a auto-estima profissional dos colaboradores, melhora o compromisso, desenvolve o espírito de trabalho de equipa, simplifica os relacionamentos internos, desenvolve a cultura organizacional e melhora a motivação dos clientes internos e a satisfação dos clientes externos.

$\mathrm{Na}$ implementação do marketing interno as empresas utilizam várias estratégias como o desenvolvimento de uma cultura organizacional humanizada, a comunicação e partilha de informação, a promoção da confiança, transparência, o incentivo, o reconhecimento, o elogio e ações de "team building".

As empresas visam com a implementação do marketing interno, atrair, desenvolver e reter colaboradores qualificados, criar relacionamentos saudáveis, duradouros e produtivos, promover a harmonia e a homogeneidade interna, desenvolver uma comunicação mais democratizada, promover uma cultura organizacional integradora, motivar e satisfazer o cliente interno e externo e melhorar o desempenho global da organização.

O estudo apresenta limitações, derivadas da reduzida amostra por conveniência e do fato de avaliar os efeitos do marketing interno apenas do ponto de vista dos gestores.

Estas limitações sugerem linhas para futuras investigações, como uma amostra mais representativa da Região de Lafões que permitisse generalizar as conclusões e também, que o questionário fosse extensivo aos colaboradores, de forma a permitir uma comparação entre a opinião dos gestores e dos colaboradores. Desta forma poder-se-iam retirar conclusões sobre a eficácia da implementação do marketing interno aos dois níveis e sugerir melhorias. 


\section{REFERÊNCIAS BIBLIOGRÁFICAS}

Cataneo, D. V. dos S., Volpato, D., Vieira, A. C. P., \& Zilli, J. C. (2018). FATORES DETERMINANTES NA MOTIVAÇÃO DOS COLABORADORES DE UMA EMPRESA FAMILIAR LOCALIZADA NO MUNICÍPIO DE URUSSANGA-SC. Revista Foco, $\quad 10(2), \quad 278 . \quad$ https://doi.org/10.28950/1981223x_revistafocoadm/2017.v10i2.341

Cervi, C., \& Froemming, L. (2017). Afinal, o que é Endomarketing? Estudo das Estratégias de Endomarketing de uma Universidade Comunitária do Rio Grande do Sul. Revista de Administração Imed 7(1), 114-136.

https://doi.org/10.18256/2237-7956/raimed.v7n1p114-136

César, N. D. (2014). Comunicação interna e marketing: Grupo Sata.

(Dissertação de Mestrado, Universidade dos Açores, Açores).

Coutinho, C. (2014). Metodologia de Investigação em Ciências Sociais e Humanas: teoria e prática ( $2^{a}$ edição), Lisboa: Edições Almedina, S.A. Cunha, M., Rego, A., Cunha, R., Cardoso, C., \& Neves, P. (2016). Manual de Comportamento Organizacional e Gestão ( $8^{\mathrm{a}}$ edição). Lisboa : Editora RH, Lda.

Fortin, M. (2009). O processo de investigação - Da concepção à realização ( $2^{a}$ edição). Loures. Décarie Éditeur Inc.

Ferreira, B., Marques, H., Caetano, J., Rasquilha, L., \& Rodrigues, M. (2015). Fundamentos de Marketing. Lisboa: Edições Sílabo.

Fortin, M. (2009). O processo de investigação - Da concepção à realização. Décarie Éditeur Inc.

Freire, A. L., Woehl, S., Catapan, A., \& Bonfim, B. L. S. (2016). Comunicação interna como ferramenta de endomarketing para maximização na competitividade: Um estudo em pequenas empresas da cidade de Paranaguá no Brasil. Journal Globalization, Competitiveness and Governability, 10(2), 54-70. https://doi.org/10.3232/GCG.2016.V10.N2.03

Gil, A. (2008). Métodos e técnicas de pesquisa social ( $6^{\circ}$ edição). São Paulo: Editora Atlas S.A. 
Lindon, D., Lendrevis, J., Rodrigues, J. \& Dionísio, P. (2011). Mercator XXI - Teoria e Prática do Marketing (13 ${ }^{\mathrm{a}}$ edição). Lisboa: Publicações Dom Quixote.

Maçães, M. (2017). Marketing e gestão da relação com o cliente. Lisboa: Edições Almedina.

Oswaldo, Y. C. (2018). Endomarketing, Liderança e Comunicação: Reflexos na Organização. Revista Brasileira de Marketing, 17(01), 128-138. https://doi.org/10.5585/remark.v17i1.3773

Patrick, C., Gomes, B., Serafim, S., \& Silva, D. (2017). Análise da Motivação dos Colaboradores do Batalhão de Operações Policiais Especiais - BOPE Motivation of the Operations Employees Police Officers in the Battalion of Special Operations Squadron BOPE, (1), 24-33. https://doi.org/10.20401/rasi.3.1.127

Reis, T. A., Brugnerotto, T. dos R., Sevilha, I. C., Cremonezi, G. O. G., \& Oswaldo, Y. C. (2018). Endomarketing, Liderança e Comunicação: Reflexos na Organização. Revista Brasileira de Marketing, 17(01), $128-138$.

https://doi.org/10.5585/remark.v17i1.3773

Ribeiro, M., Passos, C., \& Pereira, P.(2018). MOTIVAÇÃO ORGANIZACIONAL: FATORES PRECURSORES DA MOTIVAÇÃO DO COLABORADOR. Gestão e Desenvolvimento, 26 (2018), 107-133

Rodrigues, A., Queirós, A., \& Pires, C. (2016). A influência do marketing interno nas atitudes e comportamentos dos colaboradores: aplicação a uma organização de cuidados sociais e de saúde. Revista Portuguesa de Saude Publica, 34(3), 292-304. https://doi.org/10.1016/j.rpsp.2016.08.001

Silva, S. M., (2013). O endomarketing como fator de sucesso nas organizações: $O$ impacto no empenhamento e na satisfação dos clientes internos da empresa PT PRO. (Dissertação de Mestrado, Instituto Politécnico de Lisboa).

Teixeira, S. (2013). Gestão das organizações (3 $3^{\text {a }}$ edição). Lisboa: Escolar Editora. 